\title{
Pengaruh Servant Leadership terhadap Nilai Kinerja Guru
}

\author{
Bakry Bakry; Syamril Syamril \\ Institut Teknologi dan Business Kalla, Makassar \\ Jl. Urip Sumoharjo, Panaikang, Kec. Panakkukang, Kota Makassar, Sulawesi Selatan \\ bakry@kallabs.ac.id
}

Article received : September 2020; revised : Oktober 2020 ; accepted : January 2021

DOI : 10.17977/um025v5i12020p24

\begin{abstract}
Servant leadership is a form of leadership which is oriented to serve the needs of subordinates in order to improve their pay scale. The term of servant leadership was first introduced by Robert K. Greenleaf in 1970. Servant leadership can be implemented in educational institution. School as one of those intuition that runs teaching and learning process is highly determined by the practices of servant leadership performed by the principal. This research aims at investigating the effect of servant leadership on teachers and employees at Sekolah Islam Athirah Makassar. This is a quantitative research using regression analysis in analyzing the data. The variables of this research are servant leadership (X) and teachers and employees grade performance $(\mathrm{Y})$. The total participant is 90 which was taken randomly from each unit including primary school (SD), junior high school (SMP), and senior high school (SMA). The result of regression analysis showed that there was significant effect by $0,02<0,05$. It can be concluded that the $\mathrm{X}$ variable has effect on $\mathrm{Y}$ variable. In addition, it is obtained that t-test is higher than t-table $(2.297>1.991)$ which means Ho is rejected and there is effect of servant leadership on teachers and employees' performance grade. The regression equation obtained is $\mathrm{Y}=76,058+0,187 \mathrm{X}$.
\end{abstract}

Keywords: servant leadership, teacher performance

Abstrak: Servant leadership atau kepemimpinan yang melayani adalah konsep kepemimpinan yang pertama kali diperkenalkan oleh Greenleaf (1970) yang dimaksudkan sebagai bentuk kepemimpinan yang berorientasi pada sifat melayani kepentingan bawahan agar mereka menjadi lebih sejahtera. Praktik kepemimpinan yang melayani (servant leadership) juga dapat dilaksanakan pada institusi pendidikan. Sekolah sebagai institusi pendidikan yang menjalankan proses pendidikan dan pembelajaran bagi peserta didik sangat ditentukan oleh praktik kepemimpinan yang dijalankan oleh kepala sekolah. Penelitian ini bertujuan menganalisis pengaruh kepemimpinan yang melayani (servant leadership) terhadap kinerja guru dan karyawan di Sekolah Islam Athirah Makassar. Metode penelitian kuantitatif dengan menggunakan analisis regresi, variabel penelitian adalah servant leadership (X) dan nilai kinerja guru dan karyawan (Y), jumlah sampel sebanyak 90 orang guru dari unit SD, SMP dan SMA. Bedasarakan analisis regresi diperoleh nilai signifikan $0,02<0,05$ sehingga disimpulkan bahwa variabel $\mathrm{x}$ berpengaruh terhadap variabel $\mathrm{Y}$. Pada nilai $\mathrm{t}$ diperoleh thitung $>$ ttabel $(2,297>1,991)$ sehingga $\mathrm{H} 0$ ditolak artinya ada pengaruh servant leadership terhadap nilai kinerja guru dan karyawan. Dengan Persamaan Regresi yang terbentuk adalah $\mathrm{Y}=76,058+0,187 \mathrm{X}$.

Kata Kunci: servant leadership, kinerja guru 
Dalam sebuah organisasi kepemimpinan merupakan faktor kunci untuk meningkatkan performa organisasi. Praktik kepemimpinan yang baik telah terbukti mempunyai dampak terhadap semua aspek pada organisasi tersebut. Gaya kepemimpinan juga terus mengalami perubahan, mulai dari kepemimpinan transaksional, transformatif hingga kepemimpinan yang melayani (servant leadership). Satuan pendidikan sebagai sebuah organisasi yang menjalankan proses pendidikan dan pembelajaran bagi peserta didik sangat ditentukan oleh praktik kepemimpinan yang dijalankan oleh kepala sekolah.

Kepemimpinan kepala sekolah sangat berperan penting dalam mengarahkan dan mengupayakan institusi pendidikan menjalankan fungsinya sebagaimana yang dimaksudkan dalam Undang-undang Nomor 20 Tahun 2003 tentang Sistem Pendidikan Nasional (Sisdiknas) pada pasal 5 ayat (5) menyatakan bahwa pendidikan diselenggarakan sebagai suatu proses pembudayaan dan pemberdayaan peserta didik yang berlangsung sepanjang hayat.

Sebagai upaya perbaikan kualitas proses pendidikan, maka praktik kepemimpinan yang melayani (servant leadership) juga telah dipraktikan dibanyak sekolah termasuk di Sekolah Islam Ahirah Makassar. Kepemimpinan kepala sekolah yang berpengaruh sistematik dan baik akan memberikan energi yang postif untuk memotivasi dan meningkatkan kinerja guru di sekolah (Tambunan, 2014). Sehingga praktik kepemimpinan yang melayani tentunya dapat dilihat pengaruhnya terhadap kinerja guru. Olehnya itu penelitian ini dilakukan untuk menganalisis pengaruh servant leadership terhadap kinerja guru di Sekolah Islam Athirah Makassar.

Servant leadership atau kepemimpinan yang melayani adalah konsep kepemimpinan yang pertama kali diperkenalkan oleh Greenleaf (1970) dengan bukunya yang berjudul The Servant as Leader. Kepemimpinan pelayan dimaksudkan untuk lebih peduli pada lingkungan masyarakat. Kepemimpinan yang melayani pada organisasi membawa pengaruh pada kepedulian pimpinan terhadap karyawan. Sehingga servant leadership pada dasarnya bertujuan untuk meningkatkan kinerja karyawan. Dengan menjalankan servant leadership, diharapkan dapat meningkatkan job performance dari para karyawan. Hal tersebut juga didukung oleh penelitian Zehir et al. (2013) yang mengatakan bahwa servant leadership memiliki dampak pada kinerja karyawan dan berkontribusi dalam kinerja organisasi.

Selain hal tersebut, aspek kinerja dapat digambarkan sebagai: (1) hasil kerja, yaitu bagaimana seseorang mendapatkan sesuatu yang dikerjakan; (2) kedisiplinan, yaitu ketepatan waktu dalam menjalankan dan menyelesaikan tugas; (3) tanggung jawab, yaitu seseorang bekerja dengan baik meskipun tanpa diawasi; dan (4) kerja sama, yaitu kemampuan seseorang berbagi dan bekerja dengan tim untuk mencapai tujuan organisasi. Aspek tersebut diungkapkan oleh Mangkunegara (2005) menyatakan bahwa kinerja karyawan adalah hasil kerja secara kualitas dan kuantitas yang dicapai oleh seseorang karyawan dalam menjalankan tugasnya sesuai dengan tugas dan tanggung jawab yang diberikan.

\section{METODE}

Penelitian ini menggunakan metode kuantitatif, penelitian yang bersifat asosiatif dengan tujuan untuk mengetahui pengaruh ataupun hubungan antara dua variabel atau lebih (Sugiyono, 2019). Variabel dalam penelitian ini adalah servant leadership (X) dan nilai kinerja guru (Y) Sekolah Islam Athirah Makassar. Pada penelitian ini nilai kinerja diperoleh dari nilai rapor kinerja guru yang memuat aspek: (1) kompetensi inti, (2) kompetensi profesional, dan (3) tugas dan tanggung jawab sebagai guru di Sekolah Islam Athirah. Nilai kinerja diperoleh dari capaian kinerja pada semester ganjil tahun 2019/2020. Populasi dalam penelitian ini adalah seluruh guru di Sekolah Islam Athirah. Dengan menggunakan teknik pengambilan sampel acak berdasar area (cluster random sampling) diperoleh jumlah sampel sebanyak 90 guru dari unit SD, SMP dan SMA Islam Athirah Wilayah Kajaolalido dan Bukit Baruga Makassar.

Alat pengumpulan data menggunakan angket survei terkait kepemimpinan yang melayani (servant leadership) dan hasil rapor kinerja guru tahun 2019-2020, Data kemudian diolah dengan menggunakan 
analisis regresi linear sederhana. Dengan Hipotesis, $\mathrm{H} 0=$ Tidak ada pengaruh servant leadership terhadap nilai kinerja guru di Sekolah Islam Athirah. $\mathrm{H1}$ = Ada pengaruh servant leadership terhadap nilai kinerja guru di Sekolah Islam Athirah. Analisis data yang digunakan dalam riset ini adalah analisis regresi.

\section{HASIL DAN PEMBAHASAN}

Berikut disajikan hasil uji normalitas dan linearitas dengan menggunakan aplikasi SPSS 17.0 sebagai berikut (Tabel 1). Pada tabel diatas hasil uji Kolmogorov-smirnov menunjukan nilai signifikansi $0,211>0,05$ maka dapat disimpulkan bahwa nilai residual berdistribusi normal sehingga data tersebut bisa dilanjutkan pada uji regresi.

Setelah dilakukan uji normalitas kemudian dilanjutkan dengan uji linear, Pada uji linear diperoleh nilai signifikan $(\mathrm{sig})=0,104$, artinya bahwa nilai sig $0,104>0,05$ sehingga dapat dikatakan bahwa data tersebut memiliki hubungan linear. Selanjutnya setelah diketahui bahwa data berdistribusi normal dan memiliki hubungan linear maka dilakukan uji regresi linear sederhana.

Tabel 1 Uji Normalitas

\begin{tabular}{llr}
\hline & & Unstandardized Residual \\
\hline \multirow{2}{*}{ Normal Parameters } & & 90 \\
\cline { 2 - 3 } & Mean & .0000000 \\
\cline { 2 - 3 } & Std. Deviation & 9.09042528 \\
\hline Most Extreme Differences & Absolute & .112 \\
\cline { 2 - 3 } & Positive & .112 \\
\cline { 2 - 3 } & Negative & -.052 \\
\hline Kolmogorov-Smirnov Z & & 1.060 \\
\hline Asymp. Sig. (2-tailed) & & .211 \\
\hline
\end{tabular}

Analisis regresi dilakukan untuk mengetahui sebarapa besar pengaruh variabel X terhadap variabel Y. Pada penelitian ini untuk menganalisis pengaruh servant leadership (X) terhadap nilai kinerja guru di Sekolah Islam Athirah Makassar. Berikut disajikan Tabel 2 hasil analisis regresi.

Tabel 2 Nilai R Square

\begin{tabular}{ccccc}
\hline Model & R & R Square & $\begin{array}{c}\text { Adjusted R } \\
\text { Square }\end{array}$ & $\begin{array}{c}\text { Std. Error of the } \\
\text { Estimate }\end{array}$ \\
\hline 1 & $.238 \mathrm{a}$ & .057 & .046 & 9.14193 \\
\hline
\end{tabular}

Pada Tabel 2 diketahui nilai korelasi/hubungan (R) variabel servant leadership dan kinerja sebesar 0,238 dengan koefisien determinasi (R square) sebesar 0,057. Nilai tersebut menunjukkan bahwa pengaruh variabel bebas (servant leadership) terhadap variabel terikat (kinerja) sebesar 5,7\%. Sedangkan nilai signifikan dan persamaan regresi pada penelitian ini dapat dilihat pada Tabel 3.

Pada Tabel 3 Uji Regresi diatas menunjukkan bahwa nilai signifikan sebesar 0,024<0,05 sehingga dapat dinyatakan bahwa variabel $\mathrm{x}$ berpengaruh terhadap variabel $\mathrm{y}$. Kemudian setelah dilakukan uji regresi linear sederhana diperoleh nilai ttabel $=2,297$ sehingga ttabel $>$ thitung $(2,297>$ 1,991) ini menunjukkan bahwa Ho ditolak dan $\mathrm{H} 1$ diterima yaitu ada pengaruh kepemimpinan yang 
melayani (servant leadership) terhadap nilai kinerja guru di Sekolah Islam Athirah. Besarnya pengaruh variabel $\mathrm{x}$ terhadap variabel y dapat dilihat pada koefisien Nilai konstan yaitu 76,058 dan nilai servant leadership/koefisien regeresi yaitu sebesar 0,187 sehingga persamaan regresi adalah $\mathrm{Y}=76,058+$ $0,187 X$.

Tabel 3 Coefficient

\begin{tabular}{|c|c|c|c|c|c|c|}
\hline \multicolumn{2}{|c|}{ Model } & \multicolumn{2}{|c|}{$\begin{array}{l}\text { Unstandardized Coef- } \\
\text { ficients }\end{array}$} & \multirow{2}{*}{$\begin{array}{c}\begin{array}{c}\text { Standardized } \\
\text { Coefficient }\end{array} \\
\text { Beta }\end{array}$} & \multirow[t]{2}{*}{$\mathbf{T}$} & \multirow[t]{2}{*}{ Sig. } \\
\hline & & B & Std. Error & & & \\
\hline \multirow[t]{2}{*}{1} & (Constant) & 76.058 & 6.666 & & 11.409 & .000 \\
\hline & $\begin{array}{l}\text { servan_lead- } \\
\text { ership (x1) }\end{array}$ & .187 & .082 & .238 & 2.297 & .024 \\
\hline
\end{tabular}

Berdasarkan hasil analisis tersebut dapat diketahui bahwa kepemimpinan yang melayani (servant leadership) merupakan bentuk kepemimpinan kepala sekolah di Sekolah Islam Athirah memberikan pengaruh terhadap peningkatan nilai kinerja guru dan karyawan. Dari data analisis di atas yang ditunjukkan pada persamaan regresi adalah $\mathrm{Y}=76,058+0,187 \mathrm{X}$. Nilai konstanta sebesar 76,058 yang berarti bahwa nilai konsistensi variabel servant leadership dan diketahui bahwa pada setiap penambahan $1 \%$ variabel servant leadership maka terdapat penambahan $18,7 \%$ pada variabel nilai kinerja. Faktor kepemimpinan memang menjadi kunci terhadap perubahan dan perbaikan kinerja guru dan karyawan pada sebuah institusi pendidikan. Karyawan yang memiliki pemimpin dengan tipe servant leadership, lebih cenderung termotivasi melakukan inovasi-inovasi baru, untuk mencapai hasil yang diharapkan perusahaan (Wollah et al., 2020)

Hasil penelitian di atas juga didukung dengan penelitian sebelumnya terkait dengan pengaruh servant leadership terhadap nilai kinerja guru dan karyawan. Pada hasil penelitian (Tatilu et al., 2014) menyatakan bahwa penerapan servant leadership memiliki pengaruh terhadap kinerja karyawan dengan keterangan bahwa karakteristik utama yang membedakan antara kepemimpinan yang melayani dengan kepemimpinan yang lainnya adalah keinginan untuk melayani hadir sebelum adanya keinginan untuk memimpin. Pada penelitian lainya yang dilakukan oleh (Zhang et al., 2012), Servant leadership merupakan gaya kepemimpinan yang efektif karena merefleksikan penggunaan kekuatan terbaik seorang pemimpin melalui gaya melayani, dalam penelitian ini juga ditemukan bahwa seorang pemimpin yang mau 'mendengar' ada rasa 'empati' dan mengedepankan 'saling berbagi dan menghargai' adalah merupakan gaya kepemimpinan yang sangat diharapkan oleh anggota organisasi.

Servant leadership diartikan sebagai pemimpin yang paling mampu memotivasi pengikutnya dan senantiasa memprioritaskan pemenuhan kebutuhan pengikut (Liden et al., 2008). Karyawan yang memilik pemimpin dengan karakter melayani lebih cenderung termotivasi dalam melakukan inovasiinovasi baru untuk mencapai hasil yang diharapkan. Sama dengan yang dinyatakan oleh Spears (2010) yang menggambarkan servant leadership sebagai kepemimpinan yang melayani utamanya mendorong hubungan yang baik dengan mengembangkan atmosfer dignity (martabat) dan respect (hormat), membangun komunitas dan kerja tim, dan mendengarkan rekan dan karyawan.

Adapun dimensi servant leadership yang dimaksud adalah: (1) altruistic calling, menggambarkan hasrat alami yang kuat dari pemimpin untuk melayani orang lain dan membuat perbedaan positif pada kehidupan orang lain dan meletakkan kepentingan orang lain di atas kepentingannya sendiri dan akan bekerja keras untuk memenuhi kebutuhan bawahan; (2) emotional healing, menggambarkan komitmen seorang pemimpin dan keterampilannya untuk meningkatkan dan mengembalikan semangat bawahan; (3) wisdom, menggambarkan pemimpin yang mudah untuk menangkap tanda-tanda pada lingkungan, 
sehingga memahami situasi dan implikasinya; (4) persuasive mapping, menggambarkan sejauhmana pemimpin memiliki keterampilan untuk memetakan persoalan dan mengkonseptualisasikan peluang yang dapat diambil serta dapat meyakinkan seseorang untuk melakukan sesuatu tanpa terpaksa dengan memberikan alasan yang masuk akal; dan (5) organizational stewardship, menggambarkan sejauh mana pemimpin menyiapkan organisasi untuk membuat kontribusi positif terhadap lingkungan (Kwistianus \& Devie, 2015).

Olehnya itu praktik kepemimpinan yang dijalankan oleh kepala sekolah sangat terkait langsung dengan kinerja. Kinerja adalah gambaran tentang tingkat pencapaian pada pelaksanaan program yang dilakukan seseorang dalam suatu organisasi untuk mewujudkan visi, misi dan tujuan. Kinerja seseorang merupakan kombinasi dari kemampuan, usaha, dan kesempatan yang dapat dinilai dari hasil kerjanya (Sulistiyani, 2009). Sehingga kinerja harus dapat diukur untuk menganalisis dan membuat keputusan bagi organisasi untuk meningkatkan kepuasan bagi pelanggan, kualitas organisasi dapat dilihat bagaimana memberikan kenyamanan dan kepuasan kepada karyawan dalam bekerja (Azmy, 2019).

\section{KESIMPULAN}

Berdasarkan hasil analisis regresi linear sederhana diperoleh bahwa ada pengaruh servant leadership terhadap nilai kinerja guru dan karyawan di Sekolah Islam Athirah dengan nilai signifikan $0,02<0,05$. Dengan persamaan Regresi $Y=76,058+0,187 X$. Pada persamaan tersebut nilai konstanta sebesar 76,058 yang berarti bahwa nilai konsistensi variabel servant leadership dan diketahui bahwa pada setiap penambahan $1 \%$ variabel servant leadership maka terdapat penambahan $18,7 \%$ pada variabel nilai kinerja.

\section{DAFTAR RUJUKAN}

Azmy, A. (2019). Faktor-Faktor yang Mempengaruhi Kinerja Dosen Untuk Mencapai “Career Ready Professional.” JMSP (Jurnal Manajemen dan Supervisi Pendidikan), 3(3), 148-155.

Hendri Kwistianus, \& Devie. (2015). Pengaruh Servant Leadership Terhadap Employee Empowerment, Organizational Culture Dan Competitive Advantage Pada Universitas di Surabaya. Business Accounting Review, 3(2), 191-200.

Liden, R. C., Wayne, S. J., Zhao, H., \& Henderson, D. (2008). Servant leadership: Development of a multidimensional measure and multi-level assessment. The Leadership Quarterly, 19(2), 161-177. https://doi.org/10.1016/j. leaqua.2008.01.006

Mangkunegara, A. A. A. P. (2005). Evaluasi Kinerja Sumber Daya Manusia. Refika Aditama.

Spears, L. C. (2010). Character and Servant Leadership: Ten Characteristics of Effective, Caring Leaders. The Journal of Virtues \& Leadership, 1(1), 25-30.

Sugiyono. (2019). Statistik untuk Penelitian. Alfabeta.

Sulistiyani, A. T. (2009). Manajemen Sumber Daya Manusia. Graha Ilmu.

Tambunan, M., P. (2014). Pengaruh Servant Leadership Dan Kinerja Guru Terhadap Efektivitas Program Tahunan Sekolah Dasar Swasta. Jurnal Administrasi Pendidikan, 21(2), 141-150. https://doi.org/10.17509/jap.v21i2

Tatilu, J., Lengkong, V. P. K., \& Sendow, G. M. (2014). Kepemimpinan Transaksional, Transformasional, Servant Leadership Pengaruhnya Terhadap Kinerja Karyawan Pada PT. Sinar Galesong Pratama Manado. Jurnal $E M B A, 2(1), 295-304$.

Wollah, A. L., Cahyaningrum, B. N., \& Wijayanti, A. W. (2020). Pengaruh Kepemimpinan Transformasional, Servant Leadership Dan Pembelajaran Organisasi Pada Kinerja Organisasi. Journal of Business Finance and Economic (JBFE), 1(1), 45-58.

Zehir, C., Akyuz, B., Eren, M. Ş., \& Turhan, G. (2013). The Indirect Effects of Servant Leadership Behavior on Organizational Citizenship Behavior and Job Performance: Organizational Justice as a Mediator. International Journal of Research in Business and Social Science, 2(3), 1-13.

Zhang, Y., Lin, T., \& Fong Foo, S. (2012). Servant leadership: A preferred style of school leadership in Singapore. Chinese Management Studies, 6(2), 369-383. https://doi.org/10.1108/17506141211236794. 